\title{
CDKN2A NP_000068.1:p.A148T
}

National Cancer Institute

\section{Source}

National Cancer Institute. CDKN2A NP 000068.1:p.A148T. NCI Thesaurus. Code

C146950.

A change in the amino acid residue at position 148 in the cyclin-dependent kinase inhibitor

2 protein where alanine has been replaced by threonine. 